\title{
ESSENTIAL DEPENDENCE, TRUTHMAKING, AND MEREOLOGY: THEN AND NOW
}

\author{
Ross Inman
}

\begin{abstract}
One notable area in analytic metaphysics that has seen a revival of Aristotelian and scholastic inspired metaphysics is the return to a more robust construal of the notion of essence, what some have labelled "real" or "serious" essentialism. However, it is only recently that this more robust notion of essence has been implemented into the debate on truthmaking, mainly by the work of E. J. Lowe. The first part of the paper sets out to explore the scholastic roots of essential dependence as well as an account of truthmaking for accidental predications in terms of accidents. Along the way, the author examines the dialectical role the possibility of separated accidents in the Eucharist play with respect to developing a scholastic account of truthmaking as essential dependence. In conclusion the author utilises Aquinas's hylomorphic ontology to suggest a new way forward for an essentialist account of truthmaking.
\end{abstract}

\section{INTRODUCTION}

One notable area in analytic metaphysics that has seen a revival of Aristotelian and scholastic inspired metaphysics is the return to a more robust construal of the notion essence, what some have labelled "real" or "serious" essentialism. ${ }^{1}$ However, it is only recently that this more robust notion of essence has been implemented into the debate on truthmaking, mainly by the work of E. J. Lowe. The first part of the paper sets out to explore the scholastic roots of essential dependence as well as an account of truthmaking for accidental predications in terms of accidents. Along the way, I examine the dialectical role the possibility of separated accidents in the Eucharist play with respect to developing a scholastic account of truthmaking as essential dependence. I conclude by utilising Aquinas's hylomorphic ontology to suggest a new way forward for an essentialist account of truthmaking.

${ }^{1}$ See D. ODERBERG, Real Essentialism (London: Routledge, 2007) and E. J. LowE, “Two Notions of Being: Entity and Essence", in Royal Institute of Philosophy Supplement, 62 (2008): 23-24. 


\section{CONTEMPORARY TRUTHMAKING AND ESSENTIAL DEPENDENCE}

Let us, then, begin by explicating the current discussion surrounding the notion of truthmaking, with an emphasis on the notion of essential dependence. ${ }^{2}$ The fundamental insight driving the commitment to truthmakers is that truth is determined by reality. To say that something determines some particular truth is to say that it is the ontological ground of that truth; its existence explains why that truth is true. Consider the singular existential proposition that $e$ exists, $\langle e$ exists $\rangle$, and suppose that $\langle e$ exists $\rangle$ is true. Now, intuitively, it is $e$ itself that is the truthmaker for $\langle e$ exists $\rangle$ that is, $e$ determines the truth of $\langle e$ exists $\rangle$. We can call this relationship between $e$ and $\langle e$ exists $\rangle$ the relation of truthmaking, TM henceforth, and represent " $e$ is the truthmaker for $\langle e$ exists $\rangle$ " as TM $(e,\langle e$ exists $\rangle){ }^{3}$

With this in mind, let us formulate what I will call the truthmaker principle (TMP) as follows: ${ }^{4}$

(TMP) Truthmaker Principle: $\langle\mathrm{p}\rangle_{\mathrm{T}} \equiv \mathrm{E} ! x \wedge \mathrm{TM}(x,\langle\mathrm{p}\rangle)^{5}$

That is, $\langle p\rangle$ is true ( $\langle p\rangle_{T}$ henceforth) if and only if there exists something, $x$, that stands in the truthmaking relation to $\langle\mathrm{p}\rangle$. While there are many important questions regarding the notion of truthmaking operative in TMP (like the status of truthmaker maximalism, i.e. whether every truth has a truthmaker), I limit my discussion here to the status of truthmaker necessitarianism; whether the relation of truthmaking (TM) carries modal import such that the existence of the truthmaker necessitates $\langle\mathrm{p}\rangle_{\mathrm{T}}$.

The proponent of truthmaker necessitarianism claims that if $x$ is the truthmaker for $\langle p\rangle$ in some world $W$, then $x$ is the truthmaker for $\langle p\rangle$ not only in $W$ but in every possible world in which $x$ exists. Most truthmaker theorists agree that truthmakers necessitate the propositions they make true. ${ }^{6}$ We can formulate truthmaker necessitarianism as follows:

(TNec) Truthmaker Necessitarianism: $\mathrm{TM}(x,\langle\mathrm{p}\rangle) \rightarrow \square\left(\mathrm{E} ! x \rightarrow\langle\mathrm{p}\rangle_{\mathrm{T}}\right)$

${ }^{2}$ For an excellent introduction to the contemporary debate on truthmaking see GoNZALO Rodriguez-PEREYRA, “Truthmakers”, Philosophy Compass 1, no. 2 (2006): 186-200.

${ }^{3}$ I take it for granted that TM is a relation. For a denial of this assumption, see JOSEPH MELIA, "Truthmaking without Truthmakers" in Truthmakers: The Contemporary Debate, ed. H. Beebee and Julian Dodd, Oxford: Oxford University Press, 2005, 67-84. What's more, for our purposes in this paper I will generally assume that truthmaking is a cross-categorial relation that obtains between propositions (truthbearers) and entities in the world.

${ }^{4}$ I use the existence predicate ' $E$ ! $x$ ' (' $x$ exists') as shorthand for ' $\exists y(x=y)$ '.

${ }^{5}$ My quantifiers are to be taken as universal unless otherwise noted.

${ }^{6}$ Though Josh PARsons is a notable exception, see his “There is No 'Truthmaker' Argument Against Nominalism”, Australasian Journal of Philosophy 77, no. 3: 325-334. 
That is, if $x$ is the truthmaker for $\langle p\rangle$, then, necessarily, if $x$ exists then $\langle p\rangle_{T}$. In this way, the existence of $x$ is said to necessitate $\langle p\rangle_{T}$. For our purposes here, let us assume the truth of TNec, together with the rather contentious thesis that TNec, in some form or other, is both necessary and sufficient for truthmaking. If so, we then get the following explication of the notion of the truthmaking relation:

\section{(TM) Truthmaker: $\mathrm{TM}(x,\langle\mathrm{p}\rangle) \equiv \mathrm{E} ! x \wedge \square\left(\mathrm{E} ! x \rightarrow\langle\mathrm{p}\rangle_{\mathrm{T}}\right)$}

In words: $x$ is a truth-maker for $\langle p\rangle$ if and only if $x$ exists and it is necessary that if $x$ exists, then $\langle p\rangle$ is true.

Many truthmaker advocates are of the opinion that the modality operative in the above formulation of TM is to be construed as metaphysical necessity (as opposed to logical or physical necessity) such that, at the very least, $\langle p\rangle_{\mathrm{T}}$ metaphysically depends on the existence of $x$. Several truthmaker theorists, however, have expressed doubts as to whether or not standard conceptions of metaphysical necessitation - where the existence of the truthmaking entity is necessary for the truth in question - is fine-grained enough to capture the sort of dependence that obtains between a true proposition and its truthmaker(s). ${ }^{8}$

One such contemporary truthmaker theorist is E. J. Lowe. ${ }^{9}$ Following closely the influential work of Kit Fine regarding the shortcomings of modal construals of essence, Lowe questions the adequacy of standard accounts of metaphysical necessitation in its ability to capture the modal dependence operative in TM. ${ }^{10}$ Lowe critiques modal construals of TM that rely on what he calls "rigid-existential dependence", which can be formulated as follows:

(RD) $x$ depends rigidly on $y=_{\text {def }} \square(\mathrm{E} ! x \rightarrow \mathrm{E} ! y)^{11}$

As a construal of metaphysical dependence in terms of modality and existence, $\mathrm{RD}$ states that $x$ depends on $y$ just in case it is necessary that $y$ exists if $x$ exists. As an example of RD, Lowe cites the dependence of a boundary or a hole on its host or that of a heap of stones upon the individual stones that it contains. A boundary, thus, rigidly necessitates the existence of its host in that it exists only if its host

${ }^{7}$ Thanks to Jeffrey Brower for conversation on this point.

${ }^{8}$ The plural here denotes the fact that TM can be a many-many relation.

9 See E. J. LOWE, "An Essentialist Approach to Truthmaking", in Truth and Truthmaking (Acumen Press, 2008), 201-217; and The Four Category Ontology (Oxford: Oxford University Press, 2006), 192-210.

${ }^{10}$ KIT FINE, "Essence and Modality", in Philosophical Perspectives 8: Logic and Language, ed. James E. Tomberlin (Atascadero, CA: Ridgeview, 1994), 1-16.

${ }^{11}$ Alternatively, $\neg \diamond(E ! x \wedge \neg E ! y)$, i.e. $x$ cannot exist unless $y$ exists. $R D$ also goes by the name 'weak foundation' in PETER SIMONS, Parts: A Study in Ontology (Oxford: Oxford University Press, 1987), 295. 
exists. According to an understanding of TM along the lines of $\mathrm{RD},\langle\mathrm{p}\rangle_{\mathrm{T}}$ rigidly depends on the existence of $x$ such that it is necessarily the case that $\langle p\rangle_{T}$ only if $x$ exists. It is in this sense that $x$ is said to rigidly necessitate $\langle\mathrm{p}\rangle_{\mathrm{T}}$.

Lowe contends that a modal construal of TM in terms of RD leads to some rather untoward consequences, what we might generally dub the objection from irrelevance. Fundamentally, an RD reading of TM suggests that every true proposition rigidly depends on necessary beings. Again, recall that $x$ is a truthmaker for some proposition $\langle p\rangle$, say $\langle$ Socrates is pale $\rangle$, if and only if $x$ exists and it is necessarily the case that if $x$ exists, then $\langle$ Socrates is pale $\rangle$ is true. But suppose that $x$ is a necessary being, say the number 7 , and thus exists in every possible world. If the number 7 exists in every possible world, then it, ipso facto, exists in the world in which $\langle$ Socrates is pale $\rangle$ is true. It follows from this that 〈Socrates is pale〉 rigidly depends for its truth on the number 7 and, consequently, the latter is what makes the former true. ${ }^{12}$ But this seems implausible as the existence of the number 7 is wholly irrelevant regarding whether or not 〈Socrates is pale $\rangle$ is true. Though $\langle$ Socrates is pale $\rangle$ may well necessarily imply the existence of the number 7 , one is hesitant to make the further claim that therefore the number 7 is the truthmaker for 〈Socrates is pale〉.

In light of this, Lowe contends that to say that $x$ metaphysically necessitates $\langle p\rangle_{\mathrm{T}}$ is not merely to espouse the view that $x$ exists in every world in which $\langle p\rangle_{\mathrm{T}}$, i.e. that $x$ is necessary for $\langle p\rangle_{\mathrm{T}}$. Rather, metaphysical necessitation is better expressed by the fact that the non-existence of $x$ is necessary for the falsehood of $p .{ }^{13}$ Alternatively, for $x$ to be the ontological ground for $\langle p\rangle_{\mathrm{T}}$ is for $x$ 's non-existence to be necessary for the falsehood of $\langle p\rangle$. Consequently, Lowe claims that RD fails to adequately construe the modal dependence operative in TM.

Lowe maintains that the failure of RD to capture the relevant notion of metaphysical necessitation in TM does not entail that all species of metaphysical dependence are therefore inadequate to do so. In the place of RD, Lowe puts forward a relation - essential dependence - that he takes to entail rigid existential dependence, but is not entailed by it. That is, every case of essential dependence is a case of rigid-existential dependence, but not the converse..$^{14}$ As such, essential dependence is more fine-grained than rigid-existential dependence and thus is better suited to capture the notion that $\langle p\rangle_{\mathrm{T}}$ metaphysically depends on $x$. Lowe states the notion of essential dependence as follows:

${ }^{12}$ For an early statement of this sort of worry, see SIMONS, Parts, 295.

${ }^{13}$ Lowe, The Four-Category Ontology, 202.

${ }^{14}$ It should be noted that Lowe in "Two Notions of Being" takes the notion of essence to be primitive and does not reify essences. Rather, Lowe takes the locution "the essence of $x$ " to denote "what $x$ is, or what it is to be $x$ ". Further, Lowe states the fact that essential (identity) dependence entails rigid existential dependence as follows: "that if one entity depends for its identity upon another, then the former could not have existed without the latter" - LOWE, The FourCategory Ontology, 35. 
(ED) $x$ essentially depends on $y={ }_{\text {def }}$ There is a function $f$ such that it is part of the essence of $x$ that $x$ is $f(y) .{ }^{15}$

One particular example of ED would be the relationship between Socrates and his singleton \{Socrates\}, the set whose sole member is Socrates. Now, according to ED, \{Socrates\} essentially depends on Socrates precisely because it is of the essence - the very identity - of \{Socrates\} that it be the singleton set of Socrates, that is, to be the value of the singleton-set-of function, where Socrates serves as the argument.

Let us consider how ED might serve to elucidate the species of metaphysical dependence operative in TM. It is precisely in virtue of the fact that ED is more fine-grained than RD that the former is able to sidestep the objection from irrelevance. Recall that an RD reading of TM stated that $x$ is the truthmaker for 〈Socrates is pale〉 if and only if $x$ exists and rigidly necessitates the truth of 〈Socrates is pale〉, thereby allowing the unintuitive notion that every true proposition is rigidly necessitated, and thus made true, by some necessary being (the number 7). On a more fine-grained ED reading of TM, however, such an inference is unwarranted on the grounds that it is not part of the essence of 〈Socrates is pale〉 that it be true only if the number 7 exists. While $\langle$ Socrates is pale $\rangle$ might be rigidly necessitated by the number 7 , it is not essentially necessitated by it in the sense that 〈Socrates is pale does not depend for what it is - its very identity - on the existence of the number $7 \cdot{ }^{16}$ Consequently, as one cannot infer from the existence of a necessary being (number 7) that everything is essentially dependent upon it, the objection from irrelevance is avoided, thereby making essential dependence a welcome candidate for the species of metaphysical necessity operative in TM.

In the case of accidental predications, an ED reading of TM proves to be fruitful. Take, for instance, an accidental predication of the form $\langle x$ is $F\rangle$, where ' $F$ ' denotes the mode F-ness that is predicated of a substance $x$. On Lowe's four-category ontology, F-ness essentially depends on $x$ as well as the universal F (F-ness being a particularised instance of F). That is, it is part of the essence of F-ness that it (i) characterise or inhere in $x$ and (ii) be an instance of F. Since F-ness is essentially dependent on these two entities, it follows, according to Lowe, that the existence of F-ness essentially necessitates $x$ 's being $F$ and thus the truth of the proposition $\langle x$ is $F\rangle$. In other words, the existence of F-ness suffices to secure the existence

${ }^{15}$ More generally, $\exists R\left(\square_{x} R x y\right)$ : for some relation $R, x$ is essentially related by that relation to $y$. I should note that Lowe takes identity dependence to be a species of essential dependence, though I do not think this affects what I say here. For an extensive treatment of different conceptions of ontological dependence see FABRICE CORREIA, Existential Dependence and Cognate Notions (Philosophia Verlag, 2005).

${ }^{16}$ Although, as David Oderberg suggests in Real Essentialism, the number 7 is a virtual part of the essence of 〈Socrates is pale〉 in so far as the latter, an existing entity, is essentially selfidentical and thus has as a (virtual) part of its essence being distinct from the number 7 . 
of $x, \mathrm{~F}, x$ 's being $\mathrm{F}$, and therefore the truth of the proposition $\langle x$ is $\mathrm{F}\rangle$. As a result, F-ness is said to metaphysically necessitate the truth of $\langle x$ is $F\rangle$ in the right sort of way, thereby satisfying TM.

\section{SCHOLASTIC ESSENTIAL DEPENDENCE}

In spite of this recent turn to essence in the contemporary literature on truthmaking, there has been little exploration of the historical roots of the formal concept of essential dependence as it pertains to the notion of truthmaking broadly conceived. My aim in this section is to explore the scholastic roots of the notion of essential dependence as developed in the work of Duns Scotus. In section 4, I proceed to examine the relationship between Scotus's understanding of essential order with his account of truthmaking for accidental predications in terms of accidents. I then show how his account fails to satisfy the modal constraints on TM in light of his commitment to the possibility of separated accidents in the Eucharist as well as the objection from irrelevance outlined above. I conclude with a brief examination of a scholastic account of truthmaking for accidental predications that does satisfy the modal constraints of TM and thus presents itself as a viable option for contemporary truthmaker theorists.

\subsection{Scotus on Essential Order}

The notion of one entity depending on another for its existence and/or essence has a formidable history in the Aristotelian tradition. Let us begin, then, with an examination of Scotus's understanding of dependence, as displayed in his philosophical theology and substance-accident ontology.

In the context of the metaphysics of the incarnation, Scotus contends that the union that takes place between the Word, the second person of the Trinity, and the human nature of Christ (i.e. the hypostatic union) is a "union of order." ${ }^{17}$ After considering and rejecting two other kinds of unity that might obtain between the Word and the human nature of Christ, Scotus states,

All that remains therefore is the third type, namely, a union of order. The order, however, is that of the posterior to the prior. The Word obviously is not posterior to [human] nature; hence it is the other way around. The nature is posterior with respect to the Word and thus dependent on him..$^{18}$

For Scotus, then, the Word is ordered with respect to the human nature of Christ in such a way that the latter is posterior to, and thus dependent on, the former.

Scotus's most developed treatment of the notion of dependence is found in his De Primo Principio. There, he elucidates the notion of posteriority and priority,

${ }_{17}$ JoHn Duns Scotus, Quaestiones Quodlibetales [Quodl.], q. 19, n. 2.

${ }^{18}$ Ibid., n. 5. 
labelling it "essential order" and proceeds to explicate two distinct varieties of essential order: the order of eminence and the order of dependence. ${ }^{19}$ The order of eminence pertains to the notion of perfection; $x$ is eminently ordered with respect to $y$ if $x$ 's perfection (of essence) exceeds the perfection of $y$, and is thereby said to be prior to $y$ in the order of eminence. The order of dependence, on the other hand, involves the notion of priority and posteriority with respect to the essence or nature of the two relata involved; "the dependent is said to be posterior whereas that on which it depends is prior". ${ }^{20}$

Here it is crucial to note that Scotus maintains that the relata of essential ordering relations are essences (i.e. forms). Again, in the context of the hypostatic union, Scotus explicitly endorses the notion that the relata of essential ordering relations are essences, "As for the case at hand, the personal or hypostatic entity has no essential priority in respect to creatures, for an essential order obtains per se only between essences (in contrast to hypostatic entities), since it is forms (i.e. essences) that are like numbers". ${ }^{21}$ In short, the order is one of essential dependence in so far as the priority or posteriority stems from the nature or essence of the entity in question.

Scotus further suggests that essential ordering relations imply a sort of existential dependence of the posterior on that which is prior, "the prior according to nature and essence can exist without the posterior but the reverse is not true". ${ }^{22}$ He continues,

And this I understand as follows. Even though the prior should produce the posterior necessarily and consequently could not exist without it, it would not be because the prior requires the posterior for its own existence, but it is rather the other way about. For even assuming that posterior did not exist, the existence of the prior would not entail a contradiction. But the converse is not true, for the posterior needs the prior. This need we can call dependence, so that we can say that anything which is essentially posterior [in this way] depends necessarily upon what is prior but not vice versa, even should the posterior at times proceed from it necessarily. ${ }^{23}$

Following Aristotle, Scotus maintains that if $x$ is essentially posterior to $y$, then $x$ depends on $y$ for its existence. He states that if $x$ is essentially ordered to $y$, then $x$ 's existence "needs" or "requires" $y$ 's existence, i.e. it is impossible that $x$ exist without $y$ 's existing.

${ }^{19}$ John Duns Scotus, De Primo Principio [DPP $] 1.6$.

${ }^{20}$ DPP 1.8.

${ }^{21}$ Quodl. q. 19, n. 19. However, it should be noted that Scotus does, at times, allow for a wider variety of relata in essential ordering relations. See Quodl. 19., a. 2, n. 30 where he distinguishes different conceptions of essential dependence by their different relata.

${ }^{22}$ DPP 1.8.

${ }^{23}$ DPP 1.8. 
Here, however, we must proceed with caution. The claim that $x$ is existentially dependent on $y$ admits of two readings, each differing in its respective scope. We have already encountered the strong variety of existential dependence in Lowe's explication of rigid-existential dependence (RD) above. Recall that this stronger notion stated that necessarily, $x$ exists only if $y$ exists, $\square(E ! x \rightarrow E ! y)$, where ' $y$ ' denotes some particular entity such that necessarily, $x$ exists only if that particular $y$ exists. While rigid-existential dependence captures the notion of an entity's existence requiring the existence of a particular entity, the weaker reading captures the notion of an entity's existence requiring the existence of an object of a particular sort. As such, the weaker reading states that necessarily, $x$ exists only if $\mathrm{F}$ exists, where ' $\mathrm{F}$ ' is a general term denoting some instance of the class of Fs. Thus, on this weak reading, $x$ cannot exist unless something is an F, i.e. $\square(\mathrm{E} ! x \rightarrow \mathrm{E} ! \mathrm{y} \wedge \mathrm{Fy})$. Let us follow Lowe once more and label this weak variety of existential dependence "non-rigid existential dependence".

In the passage above it is not clear as to which notion of existential dependence Scotus takes essential order to entail. For now, let us just say that if an entity is essentially ordered to another entity, then the former is existentially dependent on the latter in some sense or other (understood in a wide enough sense to capture both rigid and non-rigid existential dependence).

Let us, then, formulate Scotus's conception of essential order using our sentential operator ' $\square_{\mathrm{x}}$ ' to stand for 'it is part of the essence of $x$ ':

(EO): $x$ is essentially ordered to $y \equiv \square_{\mathrm{X}}(\mathrm{E} ! x \rightarrow \mathrm{E} ! \mathrm{y})^{24}$

That is, $x$ is essentially ordered to $y$ if and only if $x$ is essentially such that it exists only if $y$ exists. Michael Gorman has pointed out that Scotus puts forward of several formal features that govern EO in De Primo Principio 2: irreflexivity, asymmetry, and transitivity. ${ }^{25}$ Using " $\square$," to stand for "essentially ordered", Scotus maintains that EO is governed by the following axioms:

Irreflexivity: "Nothing whatever is essentially ordered to itself." 26 $\neg\left(\square_{0}(x, x)\right)$

${ }^{24}$ Scotus defines "of the essence of $x$ " (what I am referring to in EO above as "part of the essence of $x$ such that") as "that which is included per se in the quidditative concept of $x$ and therefore, is posited in the essential notion of its quiddity, and not as something added." See JoHn Duns SCOTUS, Quaestiones super libros Metaphysicorum Aristotelis [In Met.] VII, q. 1.

${ }^{25}$ Michael Gorman, “Ontological Priority and John Duns Scotus”, in The Philosophical Quarterly 43 (173) (1993): 460-471.

${ }^{26}$ DPP 2.2 . 
Asymmetry: "In any essential order a circle is impossible." ${ }^{27}$

$$
\square_{0}(x, y) \rightarrow \neg \square_{0}(y, x)
$$

Transitivity: "What is not subsequent to the prior is not subsequent to the posterior" 28$$
\left(\square_{0}(x, y) \wedge \square_{0}(y, z)\right) \rightarrow\left(\square_{0}(x, z)\right)
$$

Consequently, what emerges from our above discussion of Scotus's conception of dependence is a partial ordering relation that obtains between essences that is governed by the axioms of irreflexivity, asymmetry, and transitivityThough essential order is commonly understood within the context of distinguishing per se and per accidents causal series, Scotus takes essential ordering relations to be commonplace, especially as it pertains to his substance-accident ontology. ${ }^{29}$ In attempting to distinguish essential order from any sort of causal dependence, he suggests that essential order "can be shown somehow in [the relation of] subject and accident." ${ }^{30}$ What's more, referring again to the essential order that obtains in the hypostatic union, Scotus notes that the human nature of Christ is dependent on the Word such that the latter sustains the former in existence and, further, that this sustenance is "maximally similar to that of an accident by its subject". ${ }^{11}$

But how exactly does Scotus conceive of the relation between a substance and its accidents? The issue, as we will see shortly, is complicated given his commitment to the Eucharistic doctrine that upon consecration the accidents of the bread and the wine remain in existence, even though their underlying substance ceases to exist. ${ }^{32}$ Let us turn, then, to examine Scotus's notion of EO as applied to his understanding of the relation between a substance and its accidents with an eye on the prospects of its application to the notion of truthmaking below.

Scotus operates out of an Aristotelian ontology where substances are the fundamental units of being and accidents are taken to inhere in substances. By an accident "inhering" in a substance, Scotus means to convey either: (i) the actual union of an existing accident with its existing subject as a kind of act with the potential or (ii) the dependence of the accident upon the substance, where the

${ }^{27}$ DPP 2.4.

${ }^{28}$ DPP 2.6.

${ }^{29}$ DPP 1.

${ }^{30}$ Ord. III, dist. 1, q. 1, n. 3, as cited in RICHARD CROSS, The Metaphysics of the Incarnation: Thomas Aquinas to Duns Scotus (New York: Oxford University Press, 2002), 123.

${ }^{31}$ Ord. III, dist. 1, q. 4, n. 2, as cited in CRoss, ibid.

${ }^{32}$ For an excellent treatment of the Eucharist and its role in scholastic metaphysics, see MARILYN MCCORD ADAMS "Aristotle and the Sacrament of the Altar: A Crisis in Medieval Theology", Canadian Journal of Philosophy, Supplementary Volume 17 (1991): 195-249. 
substance is essentially prior and the accident is naturally posterior. ${ }^{33}$ Regarding (i), we can say that if $x$ inheres in $y$ then $x$ actualises some potency in $y$, call this 'inherence ${ }_{A}$ ' as it underscores the fact that $x$ informs $y$ in such a way that $y$ 's passive potency (to be $x$ ) is actualised by $x$. Concerning (ii), if $x$ inheres in $y$, then $x$ is dependent on $y$ for its continued existence, call this 'inherence $e_{D}$ ' (to be read in the broadest terms to include rigid and non-rigid existential dependence). By claiming that accidents are "naturally posterior" to substances, Scotus means that "the natural entity of these [accidents] is through substance". ${ }^{44}$ That is, it is the natural order of things that accidents depend on substances as external, efficient causes of their continued existence.

Furthermore, Scotus is clear that inherence ${ }_{D}$ is more fundamental than inherence ${ }_{\mathrm{A}}$ in so far as an accident's (natural) dependence on substance serves as the ground for its capacity to actualise some potency in its substance. If an accident, F-ness, is to actualise some potency in Socrates (inherence ${ }_{\mathrm{A}}$ ), to be pale for instance, then there must be a sense in which F-ness depends on Socrates (i.e. inherence $\mathrm{D}_{\mathrm{D}}$ ) as opposed to Crito, say.

Scotus further distinguishes two ways an accident may inhere simpliciter (i.e. inhere ${ }_{\mathrm{A}}$ or inhere $\mathrm{D}_{\mathrm{D}}$ ) in a substance: actual inherence and aptitudinal inherence. ${ }^{35}$ Heavily influenced by the Eucharistic doctrine concerning separated accidents (i.e. accidents that no longer depend on their host substance for their sustained existence), Scotus argues that while it is not of the essence of an accident to actually inhere simpliciter in a substance (as is the case with separated accidents present in the Eucharist), it is of the essence of an accident that it aptitutidinally inhere simpliciter in a substance (the separated accidents are such that they naturally tend to inhere in a substance, though it is not part of their essence that they actually do so).$^{36}$ Hence, the aptitude or disposition to inhere ${ }_{\mathrm{A}}$ and inhere $\mathrm{D}_{\mathrm{D}}$ in a substance is part of the essence (what Scotus calls the "quidditative concept") of an accident, irrespective of whether or not it actually does so. Consequently, we have the following classification of accidental inherence:

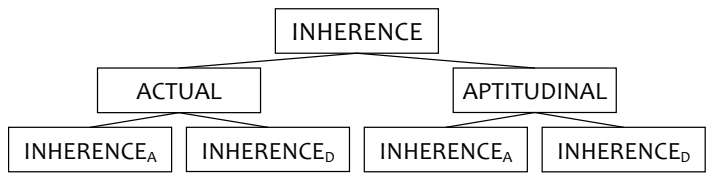

${ }^{33}$ Quodl. q. 19, n. 13; In Met. VII, q. 1, n. 9. However Scotus intends the modal import of 'natural' here, I understand it to be (at the very least) weaker than metaphysical necessity (broad logical necessity) as construed by contemporary philosophers. See CRoss, The Metaphysics of the Incarnation, 104 for more on Scotus's view of accidents being naturally posterior to substances.

${ }^{34}$ In Met. VII, q. 4, n. 2.

${ }^{35}$ See In Met. VII, q. 1, n. 10; and Quodl. q. 19, n. 24.

${ }^{36}$ In Met. VII, q. 1, n. 12. 
One apparent implication of Scotus's metaphysics of the Eucharist for his substance-accident ontology (and for his view of truthmaking as we will see shortly) is that while an accident may be naturally ordered to substance, it is not essentially ordered (posterior) to it. ${ }^{37}$ The reasoning here is straightforward. In so far as it is metaphysically possible for an accident to exist without actually inhering $_{D}$ in a substance ${ }^{38}$ it follows that it is not part of its essence to actually inhere $_{\mathrm{D}}$ in a substance and, ipso facto, is not essentially ordered to it. This reasoning relies on Scotus's earlier contention that that which is essentially ordered is existentially dependent (in either the rigid or non-rigid sense) on that which is prior ${ }^{39}$ Here I interpret Scotus as espousing the view that that which is essentially ordered to another must actually depend for its existence on that which is prior, i.e. it must actually inhere ${ }_{\mathrm{D}}$ in either its particular host substance or some substance or other..$^{40}$ Consequently, Scotus's adherence to the metaphysical possibility of an accident existing without actually inhering in either the strong or weak sense implies that accidents are not, strictly speaking, essentially ordered to substance.

At the same time, however, Scotus does speak as though accidents, in the normal order of things, actually inhered ${ }_{\mathrm{D}}$ in a substance. In fact, he is of the opinion that accidents are (naturally) sustained in existence by their host substances in such a way that the latter is "the end term of the dependence of the actual existence of an assumed nature". ${ }^{41}$ Elsewhere, he refers to this dependence relation as the substance communicating its existence to the accident. ${ }^{42}$

In adhering to the possibility of separated accidents together with the fact that accidents do at times actually inhere $e_{D}$ in their host substances, Scotus appears to be affirming the seemingly implausible thesis that being existentially dependent is a contingent affair. In fact, Scotus says just this when he states:

${ }^{37}$ See Quodl. q. 19, n. 13. Also, as Richard Cross has shown, Scotus does provide independent philosophical argumentation in support of the thesis that accidents are not essentially ordered to their host substances. See his The Physics of Duns Scotus (Oxford: Oxford University Press, 1998), 100.

${ }^{38}$ Something Scotus explicitly affirms, "the natural entity of these [accidents] is through substance; they can [however] exist without substance with an aptitude for a subject" - In Met. VII, q. 4, n. 2). The implication here is that an accident may exist without actually inhering (simpliciter) in a substance, though it cannot exist without having the aptitude to inhere in a substance.

${ }^{39}$ DPP 1.8.

${ }^{40}$ Further evidence for this reading is found in his using the notions of actual inherence ${ }_{D}$ and essential order interchangeably (In Met. VII, q. 1, n. 9) and then, shortly after, stating explicitly that it is not of the essence of an accident that it actually inhere ${ }_{\mathrm{D}}$ (ibid., n. 12) in a substance.

${ }^{41}$ Ord. III, dist. 1, q. 5, n. 8, as cited in CROSS, The Metaphysics of the Incarnation.

${ }^{42}$ Ord. III, dist. 1, q. 5, n. 8, as cited in CROss, The Metaphysics of the Incarnation; Quodl. q. 19, n. 23. 
We show this thirdly as follows: An accident can have the mode of substance [i.e. it can exist without inhering in a substance], although not perfectly in the sense that it would be repugnant for it to depend on a subject, but in some analogous way, viz., insofar as it does not actually depend; this is seen in the case of a separated accident. $^{43}$

The way in which an accident has the mode of substance in the Eucharist is that it enjoys independent existence. Be that as it may, separated accidents remain as accidents in so far as they retain their aptitude to actually inhere ${ }_{D}$ in a substance (substances do not have this feature). Nonetheless, it remains that the view has the rather untoward consequence that being existentially dependent is a contingent matter..$^{44}$ I must, at this point, leave these interpretive niceties to those with a more detailed knowledge of the issues surrounding Scotus's ontology of accidents.

As a result, we have seen that Scotus relies on a conception of essential dependence (i.e. essential order) that is governed by (i) the notion of priority and posteriority between essences (ii) the existential dependence of the posterior on the prior (in some sense or other) and (iii) the axioms of irreflexivity, asymmetry, and transitivity. Let us turn, then, to discuss several scholastic conceptions of truthmaking for accidental predictions and their relation to the notion of essential dependence (order).

\section{SCHOLASTIC TRUTHMAKING AND ESSENTIAL DEPENDENCE}

Though the scholastics did not express the notion of truthmaking in precisely the same terms as we do today, the idea is not without witness in the Aristotelian tradition..$^{45}$ In fact, both Scotus and Aquinas, with Aristotle, adopt the fundamental intuition behind the notion of truthmaking: the dependence of truth on being. ${ }^{46}$ As John Fox has noted,

${ }^{43}$ Quodl. q. 19, n. 84.

${ }^{44}$ One rather contentious way out of this would be to suggest that while it appears that being rigidly existentially dependent is non-contingent, being non-rigidly existentially dependent might be a contingent feature of an entity (as it is a weaker dependence relation). That is, a non-rigidly dependent entity can fail to be dependent as such and yet exist nonetheless. For an excellent historical treatment of the scholastic debate concerning the view that accidents have various modes of existence (modus essendi), see ROBERT PASNAU, Metaphysical Themes 1274-1689 (Oxford: Oxford University Press, 2011).

${ }^{45}$ For ARISTOTLE, see especially Categories 14b16-23. For a defence of the thesis that the scholastics utilised a truthmaking theory of predication see JoHN Fox, "Truthmaker", Australasian Journal of Philosophy 65 (1987): 188-207; JEFFERY BROWER, "Simplicity and Aseity", The Oxford Handbook to Philosophical Theology (Oxford: Oxford University Press, 2009); TIM PAWL, A Thomistic Account of Truthmakers for Modal Truths (doctoral dissertation, St. Louis University, 2008); and CROSS, The Metaphysics of the Incarnation.

${ }^{46}$ For AQUINAS see his Quaestiones Disputatae de Veritate [QDV], q. 1, a. 2, ad 3; ibid. ad 1. For ScotUs see Ord III, dist. 6., q. 1, n. 6; Reportata Parisiensia III, dist. 1, q. 2, n. 5, as cited in CROss, The Metaphysics of the Incarnation. 
Medieval philosophers customarily defined something's whiteness, heaviness, existence, manhood, or colour, as that by which it was white, was heavy, existed, was a man, or was coloured... this 'by which' is to be elucidated in terms of truthmaking. ${ }^{47}$

For both Scotus and Aquinas, substances are "made to be" by their accidents in a qualified sense; accidents are said to actualise some potency in their substances, thereby causing substances to be in some particular manner.

In particular, Aquinas speaks of an accident being related to a substance as potency to act and that "a subject, in virtue of an accident, is in certain ways" and that "whiteness makes a potentially white human being actually white... non-essential forms make it [substance] actually exist in various non-essential modes". ${ }^{48}$ What's more, he states that, "Snow is 'white' by reason of its whiteness". ${ }^{49}$ Consequently, Aquinas emphasises the role of accidents in a substance's coming to be modified in a particular manner (although we will see shortly that his account does not appeal to accidents alone).

As for Scotus, the actualisation of passive potency in a substance by an accident is, as we have already seen, embodied in his notion of inherence A $_{\mathrm{A}}$. Scotus, like Aquinas before him, argued that Socrates is white "by the existence of a white thing". ${ }^{50}$ Following Richard Cross (2002), I take this feature of accidents to be what Scotus elsewhere calls their ability to confer existence denominatively on their respective substances. ${ }^{51}$ Consequently, both Scotus and Aquinas were of the opinion that Socrates' potency for being white is actualised by the inhering of the accident whiteness.

However, both of these thinkers differed as to the details concerning the truthmaking role for accidents. To get clear on this, let us represent their views regarding the multifaceted relationship between an accident and its substance as follows:

(A) For any accident F-ness and any substance $x$ in which F-ness inheres,

(1) F-ness existentially depends on $x$, either actually or aptitudinally.

(2) F-ness actualises $x$ 's potency to be $\mathrm{F}^{52}$

(3) F-ness is a truthmaker, such that $\langle x$ is $F\rangle$ is true..$^{53}$

${ }^{47}$ Fox, “Truthmaker", 190.

${ }^{48}$ Summa theologiae [STh] I, q. 3. a. 6 and De principiis naturae 1, respectively.

${ }^{49}$ STh III, q. 77, a. 1, ad 4.

${ }^{50}$ Ord III, dist. 6, q. 1, n. 6, as cited by CROss ibid.

${ }^{51}$ CROss, ibid., 125, n. 21. See also Ord. III, q. 6, a. 1, n. 6, as cited by CROss ibid., and In Met. VII, q. 1, n. 10.

${ }^{52}$ As with (1), F-ness may either actually or aptitudinally actualise $x$ 's potency to be F. Since both Scotus and Aquinas appear to ignore an accident's having the aptitude to actualise $x$ 's potency to be F, I focus here on an accidents actually doing so.

${ }^{53}$ Ord. I, dist. 8, pars 1, q. 4, n. 213-214, adapted from CROss, ibid., 34. 
Both Scotus and Aquinas were committed to (1) and (2) regarding the relationship between an accident and its host substance. ${ }^{54}$ However, they differ as to how (1) and (2) bear on (3), that is, the truthmaking role of accidents. Here, I consider Scotus's account of truthmaking for accidental predications and proceed to Aquinas's more detailed account in the final section.

\subsection{Scotus's account of truthmaking}

In general, Scotus construes (3) in terms of (1). In fact, Scotus is quite adamant that (3) can be understood without reference to (2). He states:

You will object: how is something formally wise by wisdom unless [wisdom] is its form? I reply: a body is animate denominatively (as it were), because the soul is its form. A human being is said to be animate essentially, and not (as it were) denominatively, because the soul belongs to him or her as a part. So being of a certain sort because of something does not require that the thing [paleness] is a form informing something [Socrates], because a form [paleness] is not a form informing the whole, even though [the whole] is said to be of a certain sort because of it. ${ }^{55}$

Thus, paleness need not actualise some passive potency in Socrates in order to serve as the truthmaker for 〈Socrates is pale). Rather, Scotus was of the opinion that the truthmaking role for accidents is best construed in terms of (1); it is in virtue of a substance $x$ 's possessing an accidental form F-ness via actual inherence $e_{\mathrm{D}}$ that it is true that $\langle x$ is $\mathrm{F}\rangle$, i.e. F-ness is the truthmaker for the accidental predication $\langle x$ is F $\rangle$. As Marilyn McCord Adams notes,

Scotus declares that ontological dependence of a broad sense property thing on a subject is sufficient for characterization. Even if whiteness did not actualise a potency in Socrates, Socrates would be the subject on which the whiteness ontologically depended and that would be enough to make it true that Socrates is white. ${ }^{56}$

Scotus's explication of truthmaking in terms of (1) instead of (2) is ultimately tied to his view that inherence ${ }_{D}$ is more fundamental than inherence ${ }_{A}$ in so far as an accident's actualising some passive potency in a substance requires that the accident depend on that very substance for its existence.

Given the earlier line of reasoning in section 2 above, however, it appears that this proposal is inadequate to secure the requisite modal strength contemporary philosophers commonly ascribe to the relation of truthmaking. Recall our earlier attempt to construe existential dependence (and hence inherence ${ }_{\mathrm{D}}$ ) in the broadest possible terms in order to allow for either a strong or weak reading (i.e. rigid or non-rigid respectively) in light of the ambiguity latent in Scotus's

${ }^{54}$ For AQUINAS, see STh III, q. 77, a. 1, ad. 2.

${ }_{55}$ Ord. I, dist. 8, pars 1, q. 4, n. 213-214, adapted from CROss, ibid.

${ }^{56}$ MARYLYN MCCORD ADAMS, Christ and Horrors (Cambridge: Cambridge University Press, 2006), 126. 
claim that essential order entails existential dependence in some sense or other. Unfortunately, we can no longer remain neutral on this matter as the tenability of Scotus's proposal of truthmaking in terms of (1) heavily depends on whether or not he understands an accident to be rigidly or non-rigidly existentially dependent on a substance.

To see this, suppose we construe (1) in terms of non-rigid existential dependence and thus explicate (3) as F-ness non-rigidly depending on $x$. On this account, the existence of F-ness does not, strictly speaking, necessitate the truth of $\langle x$ is $F\rangle$, say, Socrates' being F. Rather, at most, the existence of F-ness necessitates that some $x$ is $\mathrm{F}$, not that this particular, viz. Socrates, is $\mathrm{F}$. On this reading, the existence of F-ness could just as easily necessitate the truth of 〈Glaucon is F . Consequently, interpreting (1) in terms of non-rigid existential dependence is not strong enough to capture the modal force operative in TM.

The same fate awaits an interpretation of (1) in terms of rigid-existential dependence. As was previously demonstrated, this species of metaphysical dependence does not appear to be fine-grained enough to capture the notion of truthmaking, hence the objection from irrelevance we met in section II. As Lowe (2006) has pointed out, "a truthmaker is not, or not merely, something whose existence is necessary for the truth of a proposition but something whose nonexistence is necessary for its falsehood." ${ }^{57}$

Lastly, we might underscore here the implications of Scotus's metaphysics of the Eucharist for his account of truthmaking in terms of (1). If separated accidents are metaphysically possible, then there could be instances where the F-ness (the whiteness of the bread) of $x$ exists and yet the accidental predication $\langle x$ is $F\rangle$ ( $\langle$ the bread is white) is false given that $x$ ceases to exist altogether. Yet this undermines the fact that truthmakers are said to metaphysically necessitate their truths.

Consequently, in so far as we place any stock in the objection from irrelevance and thereby require the modal force of truthmaking to be stronger than that of rigid-existential dependence, it appears that we must bid farewell to a scholastic account of truthmaking for accidental predications in terms of accidents alone.

\subsection{Hylomorphic Truthmakers}

I want to conclude by briefly unpacking an alternative essential dependence account of truthmaking for accidental predications, one that finds its roots in the hylomorphic ontology of Thomas Aquinas. Aquinas's hylomorphic account, I believe, has much to offer the contemporary truthmaker theorist as it provides a novel alternative to tropes and states of affairs as truthmakers for accidental predications.

Though at times Aquinas speaks as though accidents alone serve as truthmakers for accidental predications in virtue of satisfying (2) above, he clearly

${ }^{57}$ Lowe, The Four-Category Ontology, 202. 
states that it is the combining of an accident and its host substance that serves as the truthmaker for accidental predications. Aquinas is clear that, "when I say, "Man is white," the cause of the truth of this enunciation is the combining of whiteness with the subject" ${ }^{58}$ Elsewhere, he makes the same point, albeit more subtly, "But the reasoning by which the affirmative enunciation, 'Man is worthy,' is true, i.e., by some worthy man existing, is the same as the reasoning by which 'Man is shameful' is true, i.e., by a shameful man existing". 59

For Aquinas, the result of the combining of seatedness and Socrates is a numerically distinct hylomorphic compound, seated-Socrates (what he calls an "accidental being" generally), whose matter is Socrates and accidental form is seatedness. And, it is the existence of this numerically distinct accidental being, seated-Socrates, which is said to ground the truth of the accidental predication $\langle$ Socrates is seated $\rangle$. As a result, Aquinas is of the opinion that what enters into the truthmaking relation for accidental predications are not accidents alone (pace Scotus), but rather a distinct mereologically complex entity that is composed of an accident and a substance.

How does Aquinas's hylomorphic proposal fair as an explication of the truthmakers for accidental predications? For one, accidental beings have the requisite modal features such that their existence essentially (as opposed to rigidly) necessitates the existence of each of their proper parts (in our example of seatedSocrates, the substance Socrates and the accidental form seatedness), thereby avoiding the objection from irrelevance.

To help bring out the modal features of accidental beings qua hylomorphic compounds, we can represent the essential and ontological priority of the parts of these compounds as being governed by the following mereological principle: necessarily, if any object $x$ is part of an accidental being, $y$, then, it is part of the essence of $y$ that if $y$ exists then $x$ is a part of $y$. As an accidental being, seatedSocrates exists and is what it is in virtue of the existence and essence of its proper parts, Socrates and seatedness.

It is precisely because accidental beings exhibit these modal features that the existence of seated-Socrates is said to essentially necessitate Socrates' being seated and not merely the co-existence of two, unrelated entities: Socrates and seatedness. In so far as the essence of seated-Socrates - its very identity - involves reference to Socrates as modified by his inhering mode of seatedness, it follows that the existence of seated-Socrates essentially necessitates Socrates' being seated and, ipso facto, the accidental truth of 〈Socrates is seated〉.

Aquinas's hylomorphic account of truthmaking for accidental predications will most likely find favour with those who are already favourably disposed

${ }^{58}$ THOMAS AQUINAS, Commentary on the Metaphysics of Aristotle IX, lect. 11, n. 1898. I owe this and the following reference to PAWL, Thomistic Account of Truthmakers.

59 Thomas AQuinas, Sententia super Peri hermenias I, lect. 11, n. 10. 
toward a hylomorphic ontology and whose aesthetic sensibilities are not offended by including what Gareth Mathews has famously dubbed 'kooky objects' in their ontology. ${ }^{60}$ Nevertheless, I take Aquinas's hylomorphic account of truthmaking to be yet another example of how a hylomorphic ontology is remarkably fecund in its application to contemporary issues in metaphysics and thus deserves to be taken seriously as a viable metaphysic of material objects.

\section{BIBLIOGRAPHY}

ADAMS, MARILYN MCCORD. "Aristotle and the Sacrament of the Altar: A Crisis in Medieval Theology”. Canadian Journal of Philosophy, Supplementary Volume (1991): 195-249.

ADAMS, MARILYN MCCORD. Christ and Horrors. Cambridge: Cambridge University Press, 2006.

AQuinas, Thomas. Translated by Fathers of the English Dominican Province. London: Burns, Oates, and Washbourne 1912-36. Reprint, New York: Benziger Brothers 1947-48. Reprint, New York: Christian Classics, 1981.

- Questiones Disputatae de Veritate: The Disputed Questions on Truth. Translated by Robert W. Mulligan, S.J. Chicago: Henry Regnery Co., 1952.

- Sententia super Metaphysicam: Commentary on the Metaphysics of Aristotle. Translated by J. P. Rowan. Chicago: Regnery, 1964.

- Sententia super Peri hermenias: Aristotle on Interpretation: Commentary by St. Thomas and Cajetan. Translated by J. T. Oesterle. Milwaukee: Marquette University Press, 1962.

- De Principiis Naturae: On the Principles of Nature. Translated by Timothy McDermott. In Aquinas: Selected Philosophical Writings. Oxford: Oxford University Press, 2008.

ARISTOTLE. The Complete Works of Aristotle: The Revised Oxford Translation. Edited by J. Barnes. 2 vols. Bollingen Series. Princeton, NJ: Princeton University Press, 1984.

Brower, JefFrey. "Simplicity and Aseity". The Oxford Handbook to Philosophical Theology. Oxford: Oxford University Press, 2009.

CoRreiA, FABRICE. Existential Dependence and Cognate Notions. Philosophia Verlag, 2005.

CROSS, RICHARD. The Metaphysics of the Incarnation: Thomas Aquinas to Duns Scotus. New York: Oxford University Press, 2002.

— The Physics of Duns Scotus. Oxford: Oxford University Press, 1998.

FINE, Kit. "Essence and Modality". In Philosophical Perspectives 8: Logic and Language, edited by James E. Tomberlin, 1-16. Atascadero, CA: Ridgeview, 1994.

FoX, JoHN. "Truthmaker”. Australasian Journal of Philosophy 65 (1987): 188-207.

GORMAN, MichAeL. “Ontological Priority and John Duns Scotus”. The Philosophical Quarterly 43 [173] (1993): 460-471.

${ }^{60}$ GARETh MATHEWs, "Accidental Unities", in Language and Logos, ed. M. Schofield and M. Nussbaum (Cambridge: Cambridge University Press, 1982). 
LOWE, E. J. The Four-Category Ontology. Oxford: Oxford University Press, 2006.

- "Two Notions of Being: Entity and Essence". Royal Institute of Philosophy Supplement, 62 (2008): 23-48. DOI:10.1017/S1358246108000568.

LOWE, E. J. and RAMI, A. Truth and Truthmaking. Acumen Press, 2008.

MATTHEWS, GARETH. "Accidental Unities". In Language and Logos, edited by M. Schofield and M. Nussbaum, 223-240. Cambridge: Cambridge University Press, 1982.

MELIA, JosEPH. "Truthmaking Without Truthmakers". In Truthmakers: The Contemporary Debate, edited by H. Beebee \& J. Dodd, 67-84. Oxford: Oxford University Press, 2005.

ODERBERG, DAVID. Real Essentialism. London: Routledge, 2007.

PARSONS, JosH. "There is No "Truthmaker" Argument Against Nominalism”. Australasian Journal of Philosophy 77, no. 3 (1999): 325-334.

PASNAU, ROBERT. Metaphysical Themes 1274-1689. Oxford: Oxford University Press, 2011.

PAWL, TIM. A Thomistic Account of Truthmakers for Modal Truths. Doctoral dissertation, St. Louis University, 2008.

ScotUs, JoHn Duns. Quaestiones Quodlibetales: God and Creatures: The Quodlibetal Questions. Translated with an introduction, notes and glossary by Felix Alluntis and Allan B. Wolter. Washington, D. C.: The Catholic University of America Press, 1975.

- Quaestiones super libros Metaphysicorum Aristotelis: Questions on the Metaphysics of Aristotle by John Duns Scotus. Edited by Girard J. Etzkorn and Allan B. Wolter OFM. St. Bonaventure, NY: The Franciscan Institute, 1997-1998.

- De Primo Principio: John Duns Scotus, A Treatise on God as First Principle. Edited by Allan B. Wolter. $2^{\text {nd }}$ edition, revised with a commentary. Chicago: Franciscan Herald Press, 1983.

Simons, Peter. Parts: A Study in Ontology. Oxford: Oxford University Press, 1987. 